\title{
DRY SLIDING WEAR AND MECHANICAL CHARACTERIZATION OF Mg BASED COMPOSITES BY UNIAXIAL COLD PRESS TECHNIQUE
}

\begin{abstract}
Dry sliding wear tests are performed on magnesium composites produced by uniaxial cold press technique by using pin-on-disc. Co-efficient of friction and wear rate of magnesium composites are measured under a load of $5 \mathrm{~N}$ and sliding velocity of $0.2 \mathrm{~ms}^{-1}$. Porosity, Vickers's micro hardness, X-Ray Diffraction (XRD) results are presented to characterize the physical and mechanical properties of magnesium composites. Worn surfaces are inspected by Scanning Electron Microscope (SEM) and Energy Dispersive X-ray Spectroscopy (EDS). Three types of wear mechanisms namely abrasive, adhesive and oxidation were observed. The wear rate was found to be low for $2 \mathrm{wt} \%$ of HAP $\left(3.6 \times 10^{-6} \mathrm{~cm}^{3} / \mathrm{m}\right)$ and co-efficient of friction was observed as 0.8 .

Keywords: Bio-degradable materials, magnesium, powder metallurgy, wear
\end{abstract}

\section{Introduction}

Generally the materials used for orthopeadic implants are metals because of their excellent mechanical properties and load bearing roles required in fracture fixation. The currently used metals for implants are stainless steel, cobalt-chromium and Titanium alloys. The main drawback of using such materials are their high density and release of high toxic ions which causes some allergenic and toxic [1-5]. Now a day's researchers are attracted by magnesium based bio-degradable materials because of its light weight and density which almost equal to human bone. Also magnesium is needed for more than 300 biochemical reactions in the human body and it is one of the essential nutrients for human body. Wear property is one of the major concern when magnesium based implants are subjected to sliding motion between bones. But wear resistance of $\mathrm{Mg}$ composites is poor when compared with other materials which are to be improved for the betterment of its usage. Cold Isostatic Pressing technique in powder metallurgy is generally used to get the uniform density and homogeneity for the product.

Henrique's et al. [6] studied and compared the different properties of CoCrMo dental alloy obtained by Casting and hot pressing technique. Results showed that the hardness of the hot pressed specimen found better when compared with the cast substrates. Also the corrosion resistances for hot press substrate are found to be better than cast substrates. The $\mathrm{Mg} / \mathrm{Ca}$ composites produced by powder metallurgy technique has good corrosion potential by increase in Ca content by forming the resistive oxide layer on the surface [7]. While implanting, the composites are subjected to sliding motion between various parts. So it is important to consider the wear behavior of composites for better understanding of internal micro structural changes during sliding. Hiratsuka et al. [8] observed the different wear mechanisms on different testing environment for pure magnesium under a load of $9.8 \mathrm{~N}$, sliding velocity of $1.6 \mathrm{~m} / \mathrm{s}$ and total sliding distance of $2.5 \times 10^{3} \mathrm{~m}$. When tested in air it exhibited an oxidation wear by forming a black color layer on the alumina surface due to the formation of magnesium oxide. In case of vacuum for the same conditions it exhibited a metallic wear and wear rate is increased significantly. Alahelisten et al. [9] studied the importance of fiber volume fraction on wear behavior of Mg AZ91 alloy reinforced with alumina fiber. The wear resistance is increased with fiber content but increasing the fiber fraction caused the reduction in solid particle erosion resistance.Huang et al. [10] investigated the tribological behavior of magnesium alloys AZ91D, AS41 and AZ91E under dry and lubricant conditions and concluded that frictional co-efficient increases with increase in load under lubricant condition and decreased with increase in load under dry condition. In both condition wear rate is increased with load applied but under lubricant condition wear rate is slightly low when compared with dry condition. Two kids of wear mechanisms are observed during sliding one is abrasive wear and other is delamination wear. In another study on effect of Si on wear behavior of Mg-Si alloys by Ajith Kumar et al. [11] was shown that addition of Si would decrease the wear rate. Different frictional coefficients are obtained with increase in Si and load which indicates the different wear mechanisms are observed. Thermal softening, plastic deformation, adhesion, abrasive and oxida-

\footnotetext{
* KONGU ENGINEERING COLLEGE,DEPARTMENT OF MECHANICAL ENGINEERING PERUNDURAI, ERODE, TAMILNADU, INDIA 
tion wear mechanisms are observed at various stages. Taltavull et al. [12] examined the dry sliding behavior of cast AM60B magnesium alloy under different sliding velocity and normal load condition and different mechanisms are observed at various levels. At low load and sliding speed conditions oxidation, adhesion and delamination are identified as main mechanism. Plastic and severe plastic deformation mechanisms are observed at high load and sliding velocity. Transition from mild to severe wear regime was also observed at a load of $40 \mathrm{~N}$ and $0.5 \mathrm{~ms}^{-1}$. Chen and Alpas [13] studied the dry sliding wear behavior of Mg AZ91 alloy against the steel counter surface on pin on disc apparatus and reported that by controlling the contact surface temperature the transition from mild to severe wear can be controlled and that the onset of the severe wear was coincides with the surface temperature of $74^{\circ} \mathrm{C}$. The wear map of AZ91 alloy contained mild and severe wear regime which has two sub-wear regimes each was also exhibited. Mild wear regime consists of oxidation and delamination wear regimes while the severe wear regimes have severe plastic wear and melt wear regimes. An et al. examined the dry sliding behavior of $\mathrm{Mg}_{97} \mathrm{Zn}_{1} \mathrm{Y}_{2}$ and AZ91 alloys in pin on disc apparatus under the load range of $20-280 \mathrm{~N}$ and $20-380 \mathrm{~N}$ with sliding velocity of $0.785 \mathrm{~m} / \mathrm{s}$. Five kinds of wear mechanisms are observed for the given condition namely abrasion, oxidation, delamination, thermal softening and surface melt. For $\mathrm{Mg}_{97} \mathrm{Zn}_{1} \mathrm{Y}_{2}$ the load between 240-280 N thermal softening mechanisms is observed in which debris are adhered to the worn surface, but after $280 \mathrm{~N}$ surface melting is observed. $\mathrm{Mg}_{97} \mathrm{Zn}_{1} \mathrm{Y}_{2}$ showed better wear behaviordue to its superior thermal stability of intermetallic compounds and high temperature mechanical properties and added that the wear behavior of these alloys can be controlled by change in microstructure and mechanical properties due to rise in surface temperature. This work describes about the development of $\mathrm{Mg}$ based composites with different $\mathrm{Wt} \%$ of Hydroxy-Apatite (HAP) and $\beta$-Tri Calcium Phosphate ( $\beta$-T.C.P) physical and mechanical characterizations are studied.

\section{Experimental procedure}

Pure Magnesium, Zinc, Manganese and silicon metal powder (99.9\% purity) and HAP $+\beta$-TCP was used. The three different weight percentage (1-3 wt. $\%$ ) of HAP $+\beta$-TCP is reinforced with Mg alloys containing 1.5 wt.\% Zn-0.5 wt.\% Mn-0.6 wt\% Si

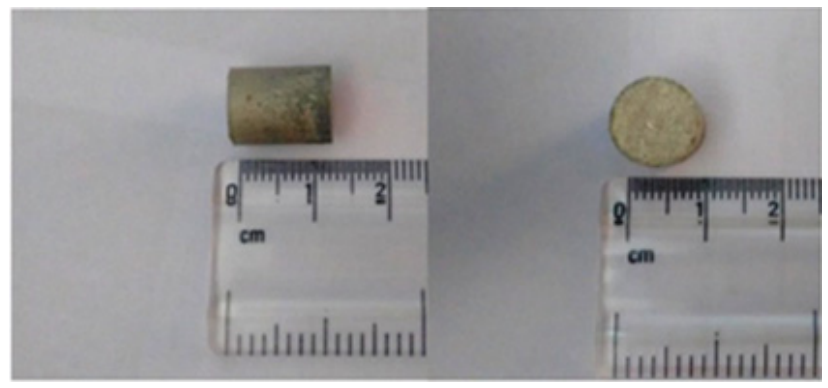

Fig. 1. Mg-H.A.P Composites and balance is Mg powder. By using rule of mixture the weight of all the respective elements are calculated. The powders are mixed well for 15 minutes and the mixed powders are processed by the uniaxial cold press technique. A specimen of size $10 \mathrm{~mm}$ diameter and $13 \mathrm{~mm}$ length is compacted as shown in Fig. 1. The pressure is maintained at $50 \mathrm{KN}$ throughout the whole process. The sintering process is carried out in the electrical resistance furnace at $280^{\circ} \mathrm{C}$ for 3 hours at controlled atmosphere. The practical densities of the composites were determined by means of Archimedes' principle. The sample was suspended in air on the spring by means of a thin thread and its weight determined as W1. It was then completely submerged in a beaker of water.

$$
\text { Density of the sample }=\mathrm{w} 1 /(\mathrm{w} 1-\mathrm{w} 2)
$$

Theoretical calculations, according to the rule of mixture, were also used to determine the densities of the composite. Then the porosity of the composite was calculated by using the formula given below.

$$
\begin{aligned}
& \text { Porosity }(\%)= \\
& \quad=(1-(\text { measureddenisty } \div \text { calculateddensity })) \times 100
\end{aligned}
$$

Microstructures were characterized using SEM. X-ray phase analysis was conducted on a Rigaku DMAX 2400 diffract meter using $\mathrm{Cu} \mathrm{K} \alpha$ radiation ( $\mathrm{Cu} \mathrm{K} \alpha, \lambda=1.5418 \AA$ ) at a scanning speed of $2^{\circ} \mathrm{min}^{-1}$. The hardness of the composite was tested with Vickers micro hardness tester.

Dry wear tests were performed using a pin on disc apparatus. The surfaces of the samples are polished manually by grit papers, and then velvet cloth polishing is carried out with alumina powder slurry using a low-speed polishing machine.

The wear tests were carried out at a low sliding velocity of $0.2 \mathrm{~ms}^{-1}$ under a constant normal load of $5 \mathrm{~N}$. The weight loss was calculated from the differences in weight of specimens measured before and after the wear tests and volumetric wear loss was estimated by dividing the weight loss by the density of the composite. Wear rates of the Mg based composite were calculated from the measured volume loss. The wear tracks and worn out surfaces were examined using scanning electron microscope.

\section{Result and discussion}

\subsection{Physical characterization}

The porosity of the composites is determined by calculated and measured densities. The porosity percentages of developed composites are shown in Fig. 3. The 3 wt $\%$ HAP $+\beta$ TCP composite showed the low porosity value which indicated that the gas entrapped between the grains is found to be low and the elements are uniformly distributed when compared to all other composites. It showed the absence of macro pores and free from high porosity. The results from Fig. 2 showed that practical densities which are almost equal to the theoretical density. 


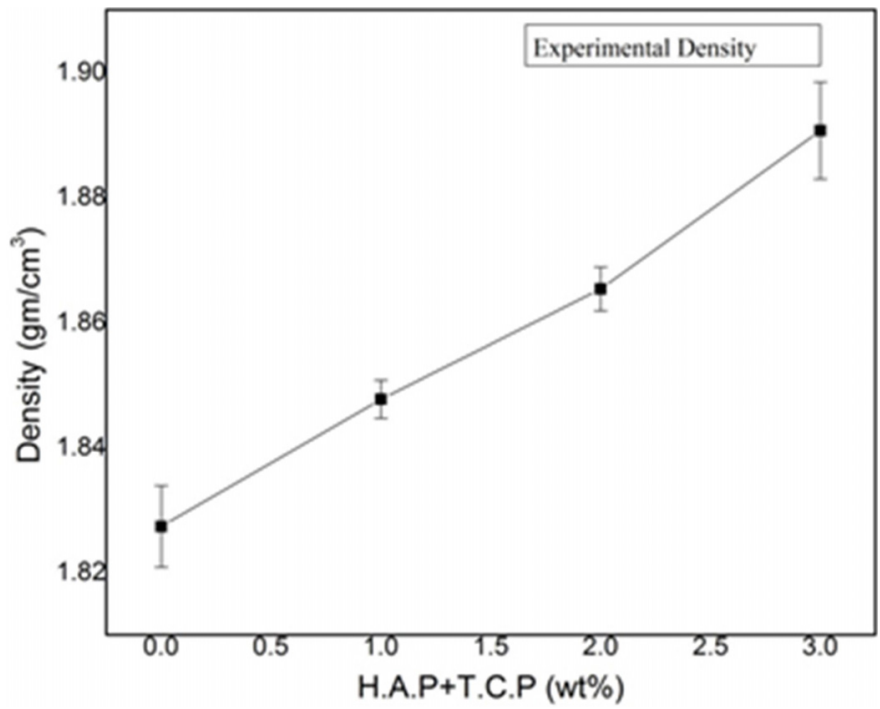

Fig. 2. Density of Mg Composites

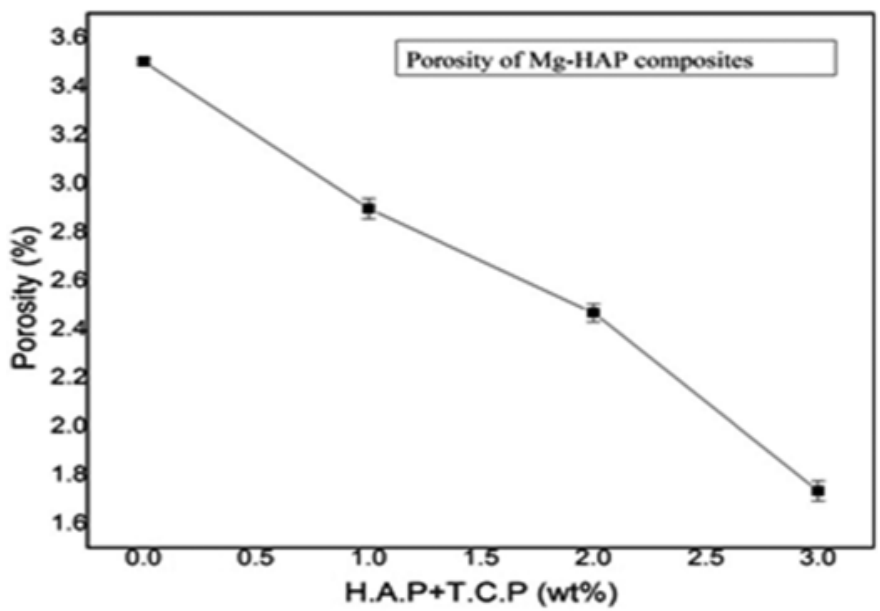

Fig. 3. S/N Response for Flank Wear

\subsection{Micro hardness}

The Vickers micro hardness of the Mg based composite is determined and tabulated in Fig. 4. The Micro hardness of composite with $2 \mathrm{wt} \%$ showed the better hardness value of 53.5 HVN. This is due to the better intermetallic bond of H.A.P with the Mg and maximum amount of solubility. After $2 \mathrm{wt} \%$ the hardness value is decreased which is due to the poor bonding capacity exhibited by Ca and the formation weak phase. Mg with $2 \mathrm{wt} \%$ H.A.P and $\beta$-T.C.P showed a better hardness value than the pure $\mathrm{Mg}$ which indicated that the $\mathrm{Mg}$ alloys are the good candidate for load bearing applications.

\subsection{XRD Analysis}

In the XRD pattern of $2 \mathrm{wt} \%$ and $3 \mathrm{wt} \%$ of H.A.P, the peak intensities are obtained at $30-40^{\circ}$ as shown in Fig. 5. Mixed patterns of $\mathrm{Mg}$ are obtained due the addition of other elements. The peaks obtained at the angles are the respective diffraction

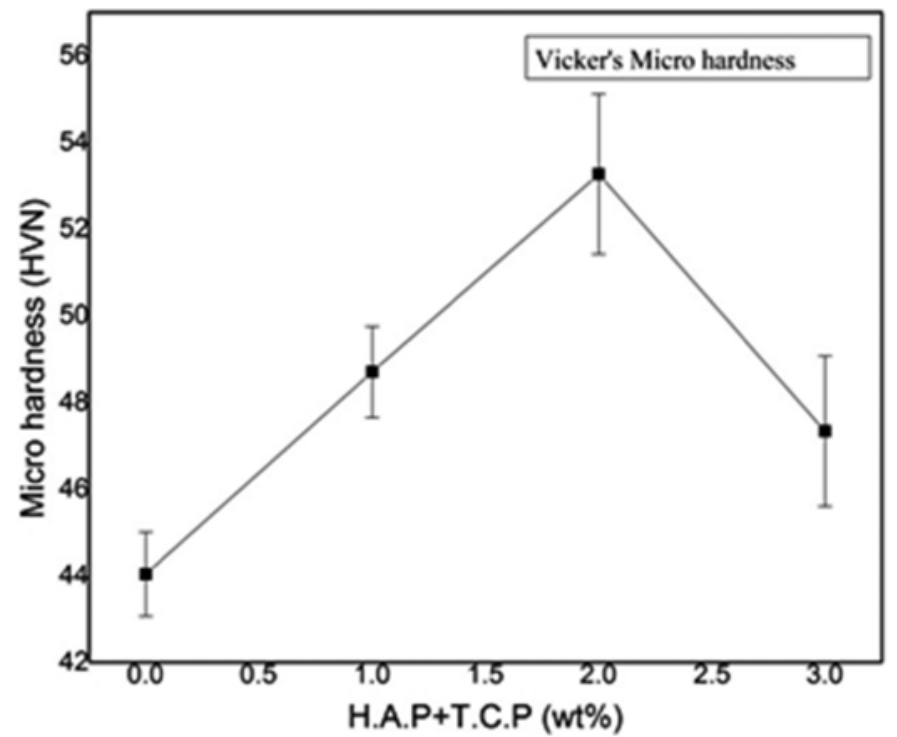

Fig. 4. Micro hardness of Mg Composites

angles of the $\mathrm{Mg}$ and other elements which also confirm that the added elements are mixed properly and reacted with $\mathrm{Mg}$ to form intermetallic compounds. These intermetallic compounds are responsible for the enhancement of properties. It can be seen that both $\mathrm{Mg}$ and H.A.P phases are identified in the composites.

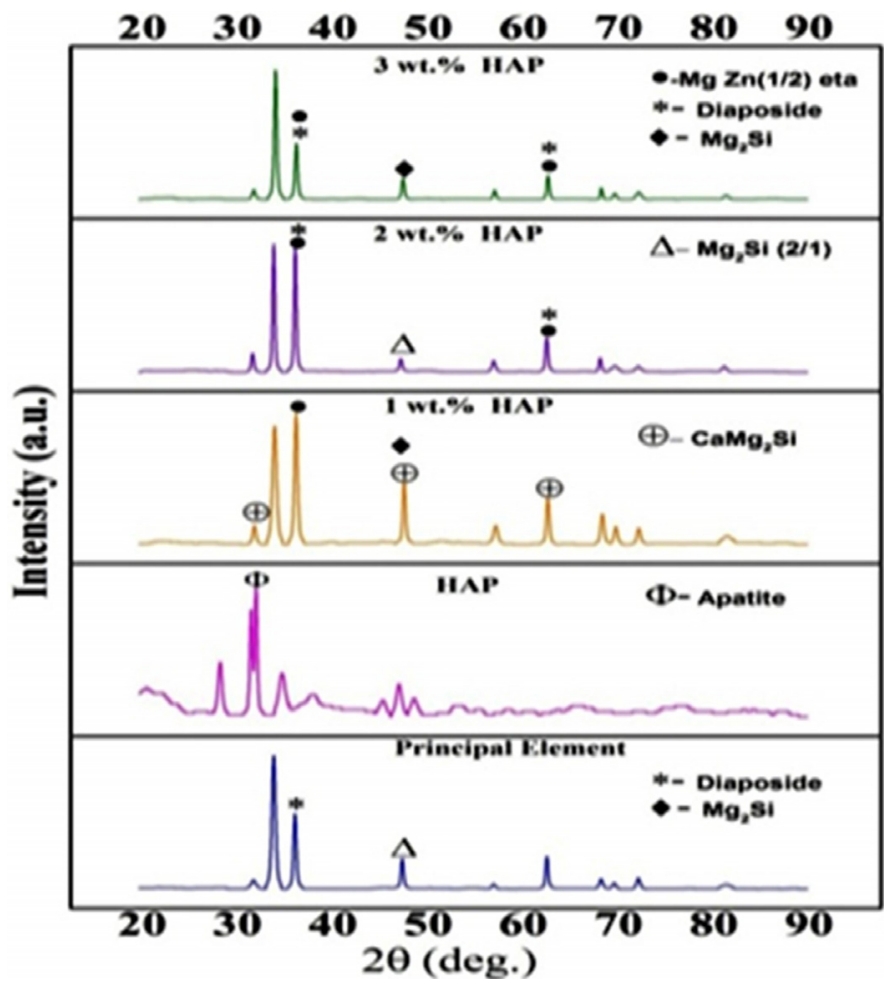

Fig. 5. XRD of Different Mg Composites

Because of adding HAP there is a formation of hydroxides of $\mathrm{Mg}$, $\mathrm{Ca}$ and mixed hydroxides. There was negligible amount of detectable trace of phases related to $\mathrm{Mg}-\mathrm{O}$ systems in the sample because of oxygen content in HAP and there will be oxide formation in the principal element. 


\subsection{Wear analysis}

The variations in coefficient of friction with time for all the composites are shown in Figure 6. Although $2 \mathrm{wt} \%$ of HAP composite showed the lower co-efficient of friction than other composites at the end of 30 mins. Except 0 wt $\%$ of HAP composite all composites are behaved same with increase in time. The friction is initially low at the time of starting due to the presence of foreign layer objects on the surface like moisture; oxide of metals. During initial rubbing this layer would breaks up and clean surface come in contact with the counter body. Also the inclusions are trapped between the surfaces would increase the ploughing action leads to high friction. The formation of oxide layer during sliding is act as a lubricant and decreases the wear. The oxide layer formed is more for $2 \mathrm{wt} \%$ H.A.P composites than other and showed the lowest wear rate at the end of sliding time (30 minutes) as shown in Table 1.

Three types of wear mechanisms are observed during the test. Abrasive wear mechanism, adhesions wear mechanism, the other is oxidation wear and it is supported by the SEM and EDS observations as shown in Fig. 7. It has been observed that the
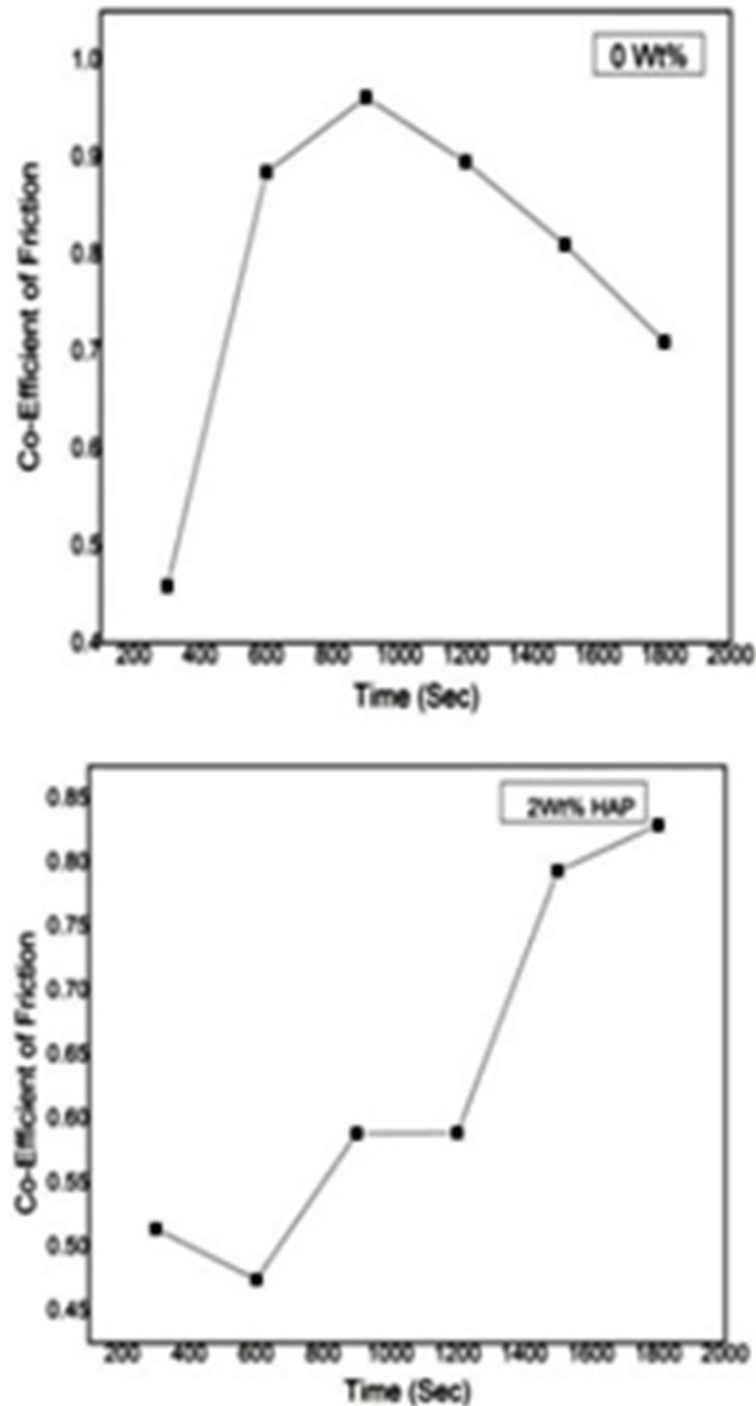

Fig. 6. Co-efficient of Friction of Mg-HAP composites
TABLE 1

Wear Rate of Mg Composite

\begin{tabular}{|c|c|c|}
\hline \hline Sl. No & Mg/HAP Composite & Wear Rate $\left.\mathbf{( c m}^{\mathbf{3}} \mathbf{m} \mathbf{m}\right)$ \\
\hline 1 & $0 \mathrm{wt} \%$ HAP & $3.69 \times 10^{-6}$ \\
\hline 2 & $1 \mathrm{wt} \%$ HAP & $6.46 \times 10^{-6}$ \\
\hline 3 & $2 \mathrm{wt} \%$ HAP & $3.60 \times 10^{-6}$ \\
\hline 4 & $3 \mathrm{Wt} \%$ HAP & $4.19 \times 10^{-6}$ \\
\hline
\end{tabular}

grooves are formed on the worn surfaces parallel to the sliding direction which is due to the abrasive wear in which the hard asperities on the counter surface would cut or plug on the pin and removed the material in the form of small fragments or ribbon like structure. These findings are in support with the findings of An et al. [14] for the dry sliding behavior of magnesium alloys Also some black colored powders are observed on the worn surfaces and the track which is due to the oxide formation results in the oxidation wear. Also the EDS analysis Fig. 8 supported the presence of oxygen peaks in addition to other elements which indicated the formation of Mg-O due to oxidation and mixed with the wear debris.
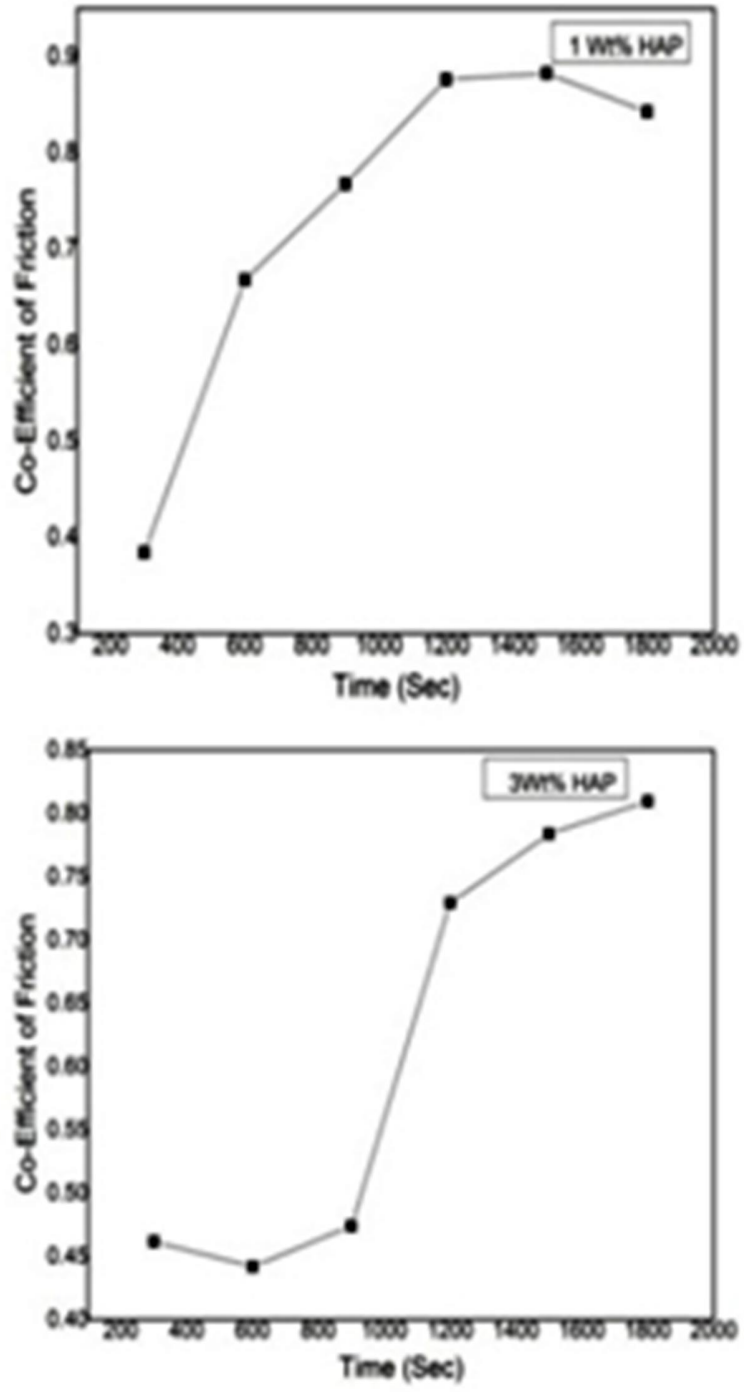

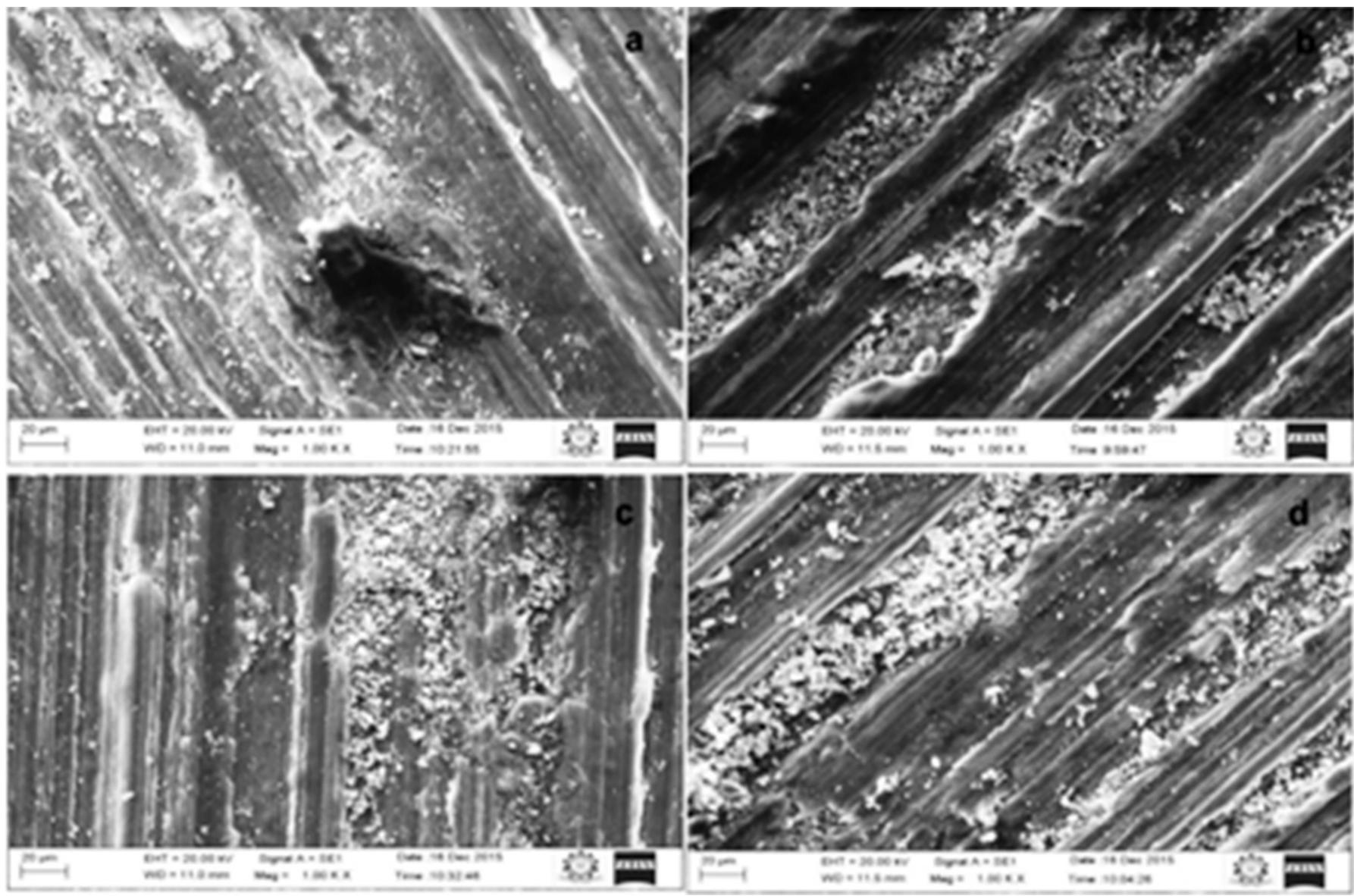

Fig. 7. SEM image of a) 0 wt $\%$ HAP Composites after wear, b) 2 wt $\%$ HAP Composites after wear, c) 1 wt $\%$ HAP Composites after wear, d) 2 wt $\%$ HAP Composites after wear. Response for Flank wear - Cutting speed vs. Depth of cut
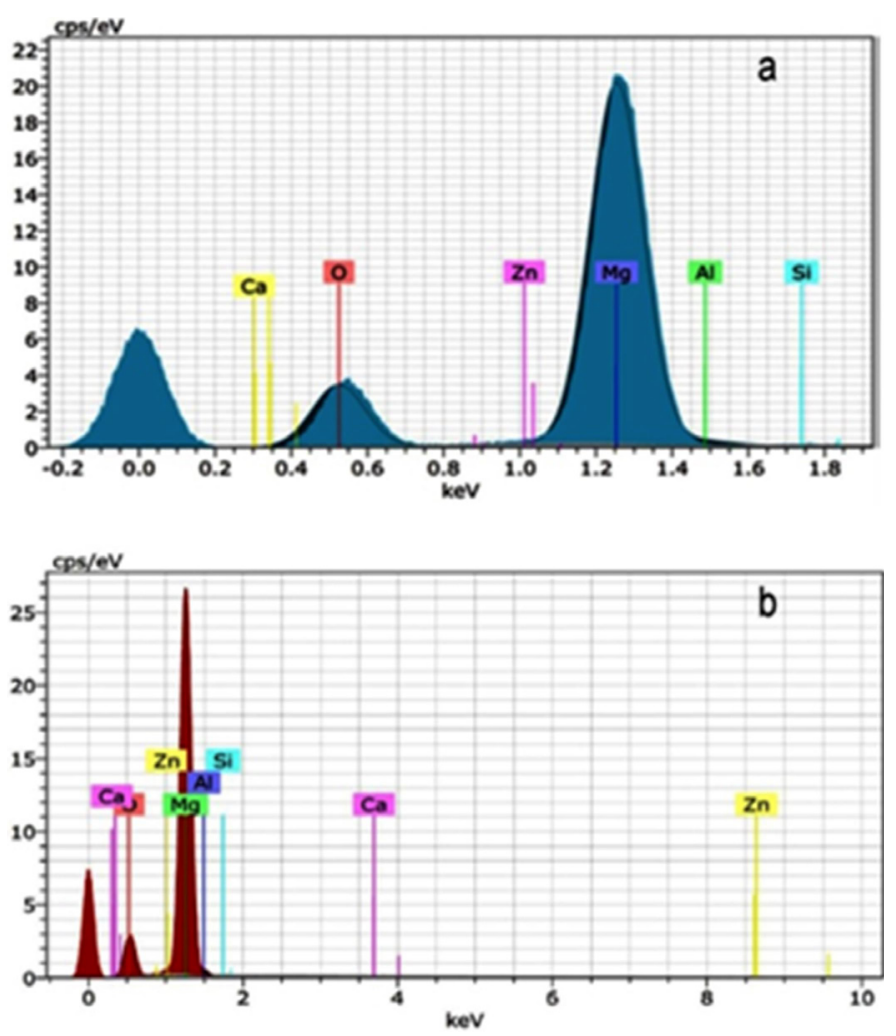

Fig. 8. EDS of a) $0 \mathrm{wt} \% \mathrm{HAP}$ ) $2 \mathrm{wt} \%$ HAP composites after wear test

\section{Conclusion}

The new magnesium based composites are developed by using uniaxial cold press technique and subjected to micro hardness test, XRD analysis and the following conclusions have been made.

1. The higher micro hardness value $(53.52 \mathrm{HVN})$ is obtained at $2 \mathrm{wt} \%$ of H.A.P $+\beta$-T.C.P due to the formation of intermetallic compounds and the hardness valuesare decreased in the order of $w \mathrm{t} \%$ of H.A.P $+\beta$-T.C.P as $2 \%<1 \%<3 \%<$ Zero.

2. The peaks obtained showed that intermetallic compounds are formed and there will not be any formation of oxides (Mg-O) which would reduce the properties.

3. Pin on Disc dry wear test on the developed composites are carried out with a constant load of $5 \mathrm{~N}$. Among the developed composites $2 \mathrm{wt} \%$ of HAP showed the low co-efficient of friction (0.8) and the wear rate $\left(3.60 \times 10^{-6} \mathrm{~cm}^{3} / \mathrm{m}\right)$. Three types of wear mechanisms such as abrasive wear, adhesion wear and oxidation mechanisms are observed while operating under prescribed conditions.

4. Because of high hardness and low wear rate the developed composite can be used in load bearing applications and act as a good candidate for bio-medical applications. 
1856

\section{REFERENCES}

[1] F. Barrere, T. Mahmood, K. De Groot,C. Van Blitterswijk, Mat. Sci. Eng. R. 59 (1), 38-71 (2008).

[2] S. Best, A. Porter, E. Thian, J. Huang, J. Eur. Ceram. Soc. 28 (7), 1319-27 (2008).

[3] S. Kannan, A. Balamurugan, S. Rajeswari, Mater. Lett. 57 (16), 2382-2389 (2003).

[4] M. Niinomi, Metall. Mater. Trans. A. 33 (3), 477-486 (2002).

[5] H. Rack, J. Qazi, Mat. Sci. Eng. C 26 (8), 1269-1277 (2006).

[6] B. Henriques, D. Soares, F. Silva, J. Mech. Behav. Biomed. Mater. 12, 83-92 (2012).

[7] E. Zhang, L. Yang, J. Xu, H. Chen, Acta Biomater. 6 (5), 17561762 (2010).
[8] K. Hiratsuka, A. Enomoto, T. Sasada, Wear 153 (2), 361-373 (1992).

[9] A. Alahelisten, F. Bergman, M. Olsson, S. Hogmark, Wear 165 (2), 221-226 (1993).

[10] W. Huang, Q. Lin, X. Zhang, P.I. Mech. Eng. J-J. Eng. 225 (1), 35-42 (2011).

[11] K.A. Kumar, U. Pillai, B. Pai, M. Chakraborty, Wear 303 (1), 56-64 (2013).

[12] C. Taltavull, B. Torres, A. Lopez, J. Rams, Wear 301 (1), 615-25 (2013).

[13] H. Chen,A. Alpas, Wear 246 (1),106-116(2000).

[14] J. An, R. Li, Y. Lu, C. Chen, Y. Xu, X. Chen, Wear 265 (1), 97-104 (2008). 